\title{
Left Vocal Cord Paralysis Secondary to Mitral Valve Disease
}

\author{
Marina $\mathrm{MB}^{\mathrm{a}}$ and Primuharsa Putra SHA \\ ${ }^{a}$ Department of Otorhinolaryngology-Head \& Neck Surgery, Universiti Kebangsaan Malaysia Medical Centre, \\ ${ }^{b}$ Ear, Nose \& Throat-Head \& Neck Consultant Clinic, KPJ Seremban Specialist Hospital
}

\begin{abstract}
Introduction: Ortner's syndrome, or cardio-vocal syndrome, is a clinical entity characterised by hoarseness (secondary to left-sided recurrent laryngeal nerve palsy) caused by cardiovascular disease. The incidence of Ortner's syndrome ranges from 0.25 percent to 0.5 percent of all cases of recurrent laryngeal nerve paralysis. Case Report: A 44-year-old Malay gentleman presented with hoarseness and shortness of breath for 4 days. It was associated with mild orthopnea and aspiration symptoms. He denied history of dysphagia, chronic cough, sore throat, chest pain, palpitation and decreased effort tolerance. There was no history of hypertension, diabetes and asthma. He also gave no history of recurrent fever with sore throat during childhood. Results: On examination, the patient appeared tachypnoeic. There was no peripheral oedema, cyanosis or clubbing. His blood pressure was $100 / 60 \mathrm{~mm} \mathrm{Hg}$ and his pulse was irregular with a rate of $78 / \mathrm{min}$. Neck examination was normal. Apex beat was not displaced. On auscultation the first heart sound was loud. A grade 3/6 long rumbling diastolic murmur was heard at the mitral area and he had bilateral basal crepitations. Laryngoscopy using 700 scope showed left vocal cord palsy in paramedian position with phonatory gap. Computed tomography (CT) of the thorax showed left atrial enlargement with prominent pulmonary veins. Echochardiography showed left atrial dilatation with thickened mitral valve. Left ventricular systolic function was good with ejection fraction of $70 \%$ and coronary angiogram showed normal coronary artery. A diagnosis of severe mitral stenosis with heart failure was made. Preoperatively the patient was stabilized and was referred for dental clearance. Then he underwent surgery for mitral and aortic valve replacement. Post-operatively patient recovered uneventfully. His hoarseness recovered completely after 3 months. Conclusion: Cardiovascular disease should be considered as a differential diagnosis in a patient with hoarseness.
\end{abstract}

KEYWORDS: Mitral valve, Ortner's syndrome, hoarseness

Corresponding author;

Dr Primuharsa Putra

KPJ Seremban Specialist Hospital, Lot 6219 \& 6220,

Jalan Toman Satu, Kemayan Square,

70200 Seremban, Negeri Sembilan

e-mail: putrani@yahoo.co.uk, primuharsa.putra@gmail.com 